\title{
¿LO MÍO Y LO TUYO? EL ESTADO KANTIANO
}

\author{
ROBERT B. PIPPIN
}

\begin{abstract}
Kant says there is a duty to exit the state of nature, to enter into a civil state. He says this is a duty of right (Rechtspflicht), not a duty of virtue. The article discusses the argument he gives to support this view, as well as the contemporary discussion on the relationship between this duty of right and the categorical imperative. The discussion is full of implications. Particularly significant is the view of the Kantian state emerging from it, which challenges the conventional account: instead of a state designed to protect pre-existing individual property rights, property rights are seen as something resulting from the very constitution of the state.
\end{abstract}

Porque si perece la justicia, carece ya de valor que vivan hombres sobre la tierra. $(6: 332 ; 105)^{1}$.

Según Kant, el estado de los individuos en mutua relación en un pueblo es el estado civil (status civilis), y el conjunto de ellos en relación a sus propios miembros es el estado (civitas) $(6: 311 ; 89)$.

1. Todas las referencias a La metafísica de las costumbres de Kant (MS de aquí en adelante corresponden a P. NATORP (ed.), Gesammelte Schriften, Königlich Preussischen Akademie der Wissenschaften (AA de aquí en adelante), (de Gruyter, Berlín y Leipzig, 1922, vol. 6). Las citas en castellano se han tomado de la traducción de A. CORTINA ORTS y J. CONILL SANCHO, Ediciones Altaya, Barcelona, 1993. 
La siguiente es una definición más completa de dicho estado o civitas: Un estado (civitas) es la unión de un conjunto de hombres bajo leyes jurídicas. En cuanto éstas, como leyes a priori, son necesarias (no estatutarias), es decir, en cuanto resultan por sí mismas de los conceptos del derecho externo en general, su forma es la de un estado en general, es decir, el estado en la idea, tal como debe ser según los principios jurídicos puros, estado que sirve de norma (norma) a toda unificación efectiva dirigida a formar una comunidad (por lo tanto, en lo interno) $(6: 313 ; 90)$.

Este estado es formalmente republicano, porque el soberano actúa en nombre de todos los individuos, y debería consistir en la separación (aunque no en un equilibrio exacto) de poderes ${ }^{2}$. La principal función del estado es la protección de los derechos de propiedad y la regulación de conflictos sobre la propiedad y los contratos, y su soberanía es absoluta (no hay ningún "derecho a la revolución"; la revolución está siempre absolutamente prohibida). Por último, la personalidad civil se limita estrictamente a lo que Kant llama ciudadanos activos, hombres adultos propietarios, y no mujeres, empleados ni "cualquiera que no pueda conservar su existencia... por su propia actividad, sino que se ve forzado a ponerse a las órdenes de otros..." $(6: 314 ; 92)$.

Por muy extremas que puedan resultarnos estas dos últimas conclusiones, esta explicación del estado encaja en una tradición liberal reconocible. Se trata de un conocido problema que concierne el uso de coacción (la amenaza de la violencia) contra individuos presumiblemente autónomos, capaces de autodeterminación ${ }^{3}$. La solución de Kant a ese problema sigue claramente uno de

2. Kant pensaba que el soberano debe reservarse el derecho a disolver o anular los otros poderes en un caso de conflicto irreconciliable; de otro modo no habríamos salido realmente del estado de naturaleza. Véase la discusión en MS $\$ 48$ y especialmente en el $\$ 49$, que trata sobre la potestas executoria.

3. Mientras que la cuestión clásica hacía referencia a "quién debería gobernar" y a otros temas afines acerca del mejor modo de asegurar la coincidencia de sabiduría y poder, y acerca de la naturaleza del conocimiento del hombre de estado, la cuestión moderna (representativa de Kant) a menudo hace referencia a la posibilidad de que exista un gobierno legítimo. A falta de una respuesta satis- 
los dos conocidos caminos diseñados por el liberalismo para abordar dicho problema. Como indican estas citas, Kant no vincula directamente la función del estado con el bienestar, la felicidad o la seguridad de sus ciudadanos, y no vincula el derecho de imponer autoridad con ningún acto de consentimiento implícito o presunto 4 . En lugar de ello, relaciona la justificación de esta autoridad con la protección de los derechos básicos compartidos por todos los seres racionales libres. Se dice que este derecho —o más bien el derecho "innato" o natural según Kant, la libertad en sus manifestaciones "externas" - sitúa a todos los demás bajo una obligación, y este hecho conforma en última instancia la base de la autoridad del estado. Dicha autoridad ha de ser la autoridad de una razón práctica no instrumental (una condición aestatal es injusta porque, en cierto sentido que se concretará más adelante, es irracional que la acepten los seres racionales o contraria a las exigencias de la razón pura práctica), pero, como indica el segundo pasaje, un estado "legítimo" ha de ser determinado por la razón pura práctica con una necesidad a priori, y por lo tanto no apela al objetivo instrumentalmente racional que supuestamente todos buscamos.

factoria, la política parecerá como consideraban Nietzsche y Weber: el uso organizado de un monopolio de violencia por un grupo contra otro.

4. Esta postura de Kant suele llamarse "contractual", pero con ello no se distinguen suficientemente las nociones empiristas o instrumentalistas del contrato originario (Locke, Hobbes, Gauthier), y Kant apela a un contrato originario sólo como una "idea" (\$47), no como una fuente que genere obligación. (Por lo tanto no como en afirmaciones tales que: "La ley debe ser obedecida porque se supone que hemos consentido su imposición"). Un contrato tal no puede ser fuente de obligación legal porque, como se señala más adelante, Kant afirma con gran claridad que tenemos el deber de salir del estado de naturaleza y formar un estado civil. La lex iustitiae o tercer "deber de justicia", de entrar en un estado civil, es una obligación que evidentemente obliga con independencia del contrato resultante. Así, aunque Kant afirme que su idea básica de justicia no tiene relación con la adopción de alguna ley que "pudiera no ser deseada por todos", es mayormente una façon de parler. Lo que efectivamente descarta una ley así sería el principio por el que dicha ley entraría en contradicción con su forma universalizada, no un intento de determinar "lo que cada uno debería desear". Cfr. la discusión recogida en L. MULHOLland, Kant's System of Rights, Columbia University Press, New York, 1990, pp. 278-80; pp. 280-93; y p. 385 ff. 
Dicha razón no respaldada por la experiencia supuestamente es capaz de justificar dos afirmaciones: por qué ha de existir esa "unión" legítima o justa, un estado, y cuáles son las características que debe tener. Esto es, Kant no sólo argumenta que un orden civil es moralmente permisible, considerando quizás como un problema la cooperación racional coherente con un status moral como ser libre y racional. Sino que, más bien considera que, cualquier persona cuya voluntad fuera permanecer en un estado pre-civil no es sólo un no-cooperador irracional, sino que es "injusto en sumo grado" ("unrecht...im höchsten Grad") $(6: 308 ; 86)$ y tal estado civil debe ser entendido como un tipo de requisito de la razón pura práctica. (Es prácticamente necesario, no sólo permisible). El problema es: ¿de qué tipo de requisito se trata $?^{5} \mathrm{El}$ deber de salir del estado de naturaleza (exeundum e statu naturali) se dice que es un deber jurídico distinto (Rechtspflicht), no de virtud, y la misma afirmación (que hay un deber de justicia) es algo esencial para la defensa kantiana del derecho, no algo suplementario 6 . Propongo discutir ahora acerca de cómo considera Kant que funciona esta justificación y qué características se derivan de ella. Este tema se ha convertido ya en un terreno relativamente familiar y las diferentes alternativas son bien conocidas; no obstante, también me gustaría apuntar que la argumentación a menudo divagatoria y confusa de Kant es, en su base, mucho más radical y sugerente que lo que se

5. Kant incluso llega a decir que la razón, "a través de un imperativo categórico, nos obliga a aspirar a" un estado civil (6:318; 95), y nombra explícitamente un "deber de justicia" (lex iustitiae) de entrar en una sociedad civil (6:237; 29). No parece referirse a un deber moral de obedecer a principios jurídicos (aunque haya uno) que pueda clasificarse por separado. En 6:220-21;22, Kant señala que la ética "tiene deberes comunes con el derecho" y que tenemos la obligación ética de cumplir con nuestro deber "venga éste de donde viniere". Así, los deberes jurídicos son también deberes "éticos-indirectos".

6. Se puede entender que Kant pregunte: "¿por qué exactamente debo yo restringir mi ejercicio de libertad externa en consideración al ejercicio similar de libertad externa de otras personas?"; la estructura de La metafísica de las costumbres sugiere inmediatamente que esta restricción no es sólo nuestra obligación moral (aunque también lo es), sino un requisito diferente y único de la razón pura práctica. De hecho, debe ser lo suficientemente único para permitir y requerir un intento colectivo que imponga obediencia mediante la amenaza del castigo, algo totalmente inapropiado en el ámbito moral. 
ha reconocido, sugerente incluso de una línea de liberalismo completamente diferente.

En el argumento básico del Rechtslehre hay dos etapas principales. La primera engloba el status de esta particular definición del concepto de derecho $\mathrm{y}$, por tanto, por qué ésta define únicamente el requisito de la razón pura práctica entre seres autodeterminados que pueden actuar externamente, i.e., que pueden actuar de tal modo que esa acción no limite la posible libertad de acción que otra persona podría tener en caso de que no actuaran. La definición del concepto de derecho es: "el conjunto de condiciones bajo las cuales el arbitrio de uno puede conciliarse con el arbitrio del otro según una ley universal de la libertad" $(6: 230 ; 24)$. Otra versión diferente de esta cuestión sería por qué nos vemos forzados y obligados en nuestras acciones "externas" por este Principio universal del derecho: "Una acción es conforme a derecho cuando permite, o cuya máxima permite a la libertad del arbitrio de cada uno coexistir con la libertad de todos según una ley universal" $(6: 230 ; 24)^{7}$.

La segunda cuestión tiene que ver con el papel tan extraordinariamente importante que este argumento concede a la propiedad. La definición del concepto de derecho hacía referencia al "conjunto de condiciones" bajo las cuales es posible un ejercicio mutuo de la libertad (sin la cual es imposible), y en el argumento principal del Derecho privado vemos que hay una condición esencial para todo establecimiento de dicha mutualidad que siga unos principios: una distinción inteligible entre lo mío y lo tuyo, o la seguridad de los derechos de propiedad, y que esta distinción puede realizarse "sólo" de un modo - "en un estado jurídico", esto es, "bajo un poder legislativo público", es decir, "en el estado civil", en un estado $(6: 255 ; 44)$ - Evidentemente, si el problema explica los requisitos de la razón pura práctica entre seres que pueden actuar de tal forma que sus acciones limiten la posible libertad de acción que en caso

7. De manera que sin duda Kant puede incluirse en esa tradición del derecho natural racional que engloba a Rousseau, Fichte y Hegel, así como a su defensor contemporáneo más influyente, John Rawls. 
de que no actuaran tendrían otras personas, la solución es: una observancia recíproca mutuamente asegurada de la frontera entre lo mío y lo tuyo. (Obviamente necesitaremos una explicación de cómo y por qué se asegura esta observancia recíproca). La institución fundamental de la sociedad burguesa moderna, según lo ve Kant, es la propiedad privada, y la autoridad fundamental del estado proviene del papel que desempeña al asegurar los derechos de propiedad. No obstante, no podemos deducir a priori qué es lo mío y qué es lo tuyo, y este hecho llevará a Kant a realizar unas afirmaciones muy interesantes y especulativas, no sólo acerca de la propiedad, sino también acerca de nuestra identidad social o concretamente práctica como agentes.

Kant quiere reivindicar que hay un estado bajo el cual pueden realizarse los derechos de justicia — los derechos de cada uno de ejercer la libertad externa de modo formalmente compatible con un ejercicio similar de los demás-. Este estado es, en general, "la salida del estado de naturaleza" (exeundum e statu naturali), el poder legislativo, ceder a una autoridad pública el derecho de decisión propio. En concreto, implica el establecimiento de fronteras entre lo mío y lo tuyo, o pasar de un derecho privado provisional a un derecho efectivo y estable. Como se ha señalado, su primer problema es aclarar qué tipo de derecho es para los demás un derecho de justicia, sobre todo porque Kant quiere por una parte distinguir entre los derechos de justicia y los derechos morales y el deber moral. Obviamente, la obediencia de los derechos de justicia puede y debe ser coaccionada, pero los deberes éticos para con los demás no pueden y no deben ser coaccionados. Coaccionar a alguien para que adopte un fin moralmente obligatorio es dejar de tratarle como un fin en sí mismo, y Kant frecuentemente deja claro 
que desprecia toda forma de paternalismo ${ }^{8}$. No obstante, la obediencia coaccionada de los derechos de justicia no implica esa falta de respeto. Más bien al contrario, como hemos visto, no conseguir forzar o apoyar un sistema de obediencia coaccionada es "injusto en sumo grado", sería no conceder a otro su status adecuado como ser racional libre, con derecho a una esfera externa en la que pueda ejercer su libertad. Y, por otra parte, pese a esta distinción que hace Kant entre derecho y moralidad, la misma forma de la Metafísica de las costumbres sugiere que los derechos o reinvindicaciones de justicia (claims of rights) son en cierto sentido un subconjunto de nuestras obligaciones morales para con los demás, que llevan a los comentaristas a buscar alguna manera de comprender los derechos o reivindicaciones de justicia (claims of rights) como una "aplicación" del principio moral supremo de Kant, el imperativo categórico; o, en otro sentido, como derivados de los requisitos de la teoría moral general de Kant. (Llamaremos a estos comentaristas "derivacionistas").

La primera demarcación oficial de Kant proporciona cierto aliento a las afirmaciones de los derivacionistas con respecto a los deberes legales. Kant contrasta las "leyes de naturaleza" con todas las "leyes de libertad" y a todas estas últimas las llama "leyes morales". Posteriormente clasifica las "leyes jurídicas" —aquellas "obligaciones referidas a acciones externas"- como subcategorías de dichas leyes morales, en función de su mera conformidad con la ley $(6: 220 ; 14)^{9}$. Y esta clasificación introduce la oposición más conocida a la que Kant casi siempre apela cuando distingue esos tipos de afirmaciones — "uso del arbitrio" (Gebrauche der Willkür) exterior versus interior-. Todas las leyes de libertad se distinguen

8. En el ensayo "Teoría y práctica", Kant llama al gobierno paternalista "el mayor despotismo pensable". I. KANT, "On the Proverb: That May Be True in Theory, But is of No Practical Use", Perpetual Peace and Other Essays, trad. Ted Humphreys, Hackett, Indianápolis, 1983. AA 8: 290; 74-4.

9. También sugiere aquí una afirmación sorprendente sobre los deberes morales: que siempre aparecen de forma dual, mandándonos tanto obedecer la ley, como hacer del respeto por la ley misma nuestro fundamento de acción (una propuesta que sugiere una extraña regresión.) Cfr. MS, 6:391; 154 sobre el "mandato ético universal: obra conforme al deber por deber". 
por el tipo de "legislación" apropiada a cada una, exterior o interior, y Kant insinúa que esto por sí solo puede definir los diferentes tipos de leyes. Las así llamadas leyes exteriores son aquéllas para las que es posible una legislación exterior (como ocurre con la amenaza de un castigo); en el caso de las leyes morales o aquéllas cuya legislación es interna, dicha coacción externa no es posible (el cumplimiento de los deberes de virtud no sería cumplimiento del deber si estuviera motivado por el miedo al castigo: no habríamos adoptado el fin). De modo que si hiciéramos una promesa, estaríamos ligados al deber de cumplirla, como un deber de moralidad, incluso si no hubiera ningún tipo de obligación externa. Pero, ya que dicho cumplimiento implica acciones del "dominio exterior", el cumplimiento coaccionado también es aquí posible. Por ello, incluso Kant dice que "cumplir las promesas no es un deber de virtud, sino un deber jurídico" (6:220; 21).

Al declarar que no se trata de un deber de virtud, quiere decir que adoptar un fin "internamente", como la perfección de nuestros talentos o la beneficencia, no es un deber. No obstante, parece que Kant sigue teniendo cierta confusión al no señalar que los deberes de virtud y las reivindicaciones jurídicas que pueden ser exigidas (enforceable rights claims) no agotan todas las categorías de obligación. Por ejemplo, hay deberes perfectos para con uno mismo que no tienen por qué implicar tal establecimiento de fines, pero que también están prohibidos por su misma naturaleza o forma como el suicidio-, y el cumplimiento de estos deberes se seguiría considerando como cumplimiento aunque no tuvieran dicha motivación interna. Con todo, no parecen ser objetos adecuados de criminalización. Del mismo modo, hay algunos deberes perfectos para con los demás que están prohibidos por su misma forma y que no requieren la adopción de ningún fin, pero que no parecen violaciones del derecho jurídico. Los casos de hacer promesas y decir la verdad son los más obvios. Yo podría abstenerme de mentir cuando hubiera podido mentir, pero por un motivo no moral, sin ninguna legislación interna, y seguiría cumpliendo mi deber. El mismo Kant admite que no todas las promesas que se rompen ni 
todas las mentiras son violaciones del derecho ${ }^{10}$. Kant señala que las mentiras que se dicen a otros no son consideradas automáticamente como violaciones del derecho, porque la persona a quien se dirigen las mentiras puede elegir creerlas o no, y no deseamos un estado paternalista que tome esas decisiones por cada individuo. (Sólo cuando alguien confía en una promesa y resulta dañado por no cumplirse ésta, entonces la violación es una violación del derecho). Así, él admite en un pie de página que efectivamente hay un problema de fronteras al esbozar lo que él llama una "línea divisoria" (Grenzlinie) entre lo que pertenece al Ius o derecho y lo que pertenece a la ética.

Necesitaríamos un artículo aparte para clasificar los diferentes usos de "exterior" e "interior", pero todo lo que hemos de apuntar aquí es que en esta discusión acerca de cuándo mentir debería ser considerado como una violación del derecho, Kant nos orienta en la dirección que he referido anteriormente. Él sigue un interesante criterio al presentar como permisible una autorización para "hacer a otros cualquier cosa que, de por sí, no les perjudica en lo suyo..." (6:238; 30, énfasis mío). Esto indica una vez más que si queremos conocer qué tipos de requirimientos o demandas (claims on others) hacia los demás son objetos adecuados de legislación, nos será más útil un análisis del problema concreto de determinar la frontera entre "lo mío y lo tuyo en la esfera externa" que cuanto podamos averiguar desde el mismo principio del derecho.

10. Los problemas suscitados por las violaciones del deber perfecto que no son objetos adecuados de criminalización son ignorados en el resumen que hace Roger Sullivan de la argumentación de Kant en su Introducción a la edición de Cambridge de MS, p. XII. Paul Guyer también suele escribir como si la categoría de deber perfecto fuera congruente con los deberes jurídicos. Véase P. GUYER, "Life, Liberty and Property", Metaphysics of Morals: Interpretive Essays M. TIMMONS (ed.), Oxford University Press, Oxford, 2002, p. 278. Para una discusión más completa sobre este tema, véase mi libro "On the Moral Foundations of Kant's Rechtslehre", Idealism as Modernism: Hegelian Variations, Cambridge University Press, Cambridge, 1997, pp. 56-91. 
ROBERT B. PIPPIN

No obstante, el problema inicial sigue siendo el siguiente: ¿qué tipo de exigencia normativa (normative claim on others) hacia los demás es una exigencia de derechos (rights claim)? En la literatura más reciente encontramos tres alternativas, y me detengo para resumirlas aquí, principalmente porque creo que de nuevo sugerirán que todas las estrategias alternativas introducen más preguntas que respuestas, lo cual insinúa indirectamente que queda mucho que aprender de lo que yo llamo el argumento "nuclear" de la Doctrina del derecho: sobre por qué es "injusto" que los seres racionales libres no cedan a la autoridad pública el poder de decidir qué es lo mío y lo tuyo.

Tal como he mencionado, en primer lugar encontramos la postura de la "derivación" directa, y ya hemos visto pasajes en los que Kant parece subsumir el principio jurídico bajo la ley moral y parece aplicar libremente nociones morales del imperativo y la obligación en un contexto político ${ }^{11}$. La teoría moral de Kant defiende el imperativo categórico como el principio moral supremo, y la misma formulación del Principio Supremo de Justicia (con su referencia a una ley universal de libertad) sugiere fuertemente que Kant tiene en mente alguna derivación de ese principio. Además, la mayor parte de los comentarios estándar sobre la Doctrina del derecho defienden la afirmación de que el principio de justicia supremo se deriva de algún modo de los elementos básicos de la teoría moral de Kant. Otfried Höffe argumentó que la teoría moral de Kant depende de un imperativo categórico "general" con formas específicas y delimitadas: una regla formal de impermisibilidad en la ética, un uso "material" de la especificación de fines obligatorios, como en la doctrina de la virtud, y una forma jurídica, mani-

11. Quizás el pasaje más claro se encuentra en MS 6:239; 31. "Conocemos nuestra propia libertad (de la que proceden todas las leyes morales, por tanto, también todos los derechos así como los deberes) a través del imperativo moral, que es una proposición que manda el deber, y a partir de la cual puede desarrollarse después la facultad de obligar a otros, es decir, el concepto de derecho". ("entwickeln" traducido frecuentemente como "desarrollarse"; énfasis mío). 
fiesta en la doctrina de Kant del Derecho Privado y Derecho Público ${ }^{12}$. Así las afirmaciones de que "como quiera que Kant separe la Ley de la Ética, no la separa desde el punto de vista moral"13. Wolfgang Kersting insiste en que "la justificación de la filosofía jurídica de Kant depende de su filosofía moral", y habla con frecuencia del "imperativo categórico de la razón en el reino del derecho"14. Mary Gregor ha afirmado fundadamente que la noción central de la teoría política de Kant, el derecho, en cuanto significa "facultad de obligar a otros", depende de un modo fundacional de una noción moral general de la obligación ${ }^{15}$. Leslie Mulholland hace un uso frecuente y explícito de lenguaje de derivación y a menudo invoca frases como un "derecho moral de obligar a otros" al analizar el pensamiento de Kant sobre los dere$\operatorname{chos}^{16}$. Hay muchas más interpretaciones. (Se podría añadir a esta lista a Bernd Ludwig, H.- F. Fulda, Roger Sullivan, Onora O'Neill y Paul Guyer).

Ahora, por lo que conozco, ninguno de los principales comentaristas que sigue esta línea comete el error de pensar que el modo en que el principio de derecho depende de los principios morales para mantener su status normativo y obligatorio quiere decir que

12. O. HÖFFE, "Kant's Principle of Justice as Categorical Imperative of Law,” Y. YOVEL (ed.), Kant's Practical Philosophy Reconsidered, Dordrecht, Kluwer, 1989, pp. 146-67.

13. Ibidem, p. 165.

14. W. Kersting, "Politics, Freedom, and Order: Kant's Political Philosophy", P. GUYER (ed.), The Cambridge Companion to Kant, Cambridge, Cambridge University Press, 1992, p. 347. Véase también su análisis más extenso en W. KERSTING, Wohlgeordnete Freiheit, de Gruyter, Berlin, 1984.

15. M. GREGOR, "Kant on 'Natural Rights", R. BEINER y W. J. BOOTH (eds.), Kant and Political Philosophy, Yale University Press, New Haven, 1993, p. 53. (En este artículo encontramos una discusión especialmente útil sobre la transición histórica desde las posturas de Grotius y Pufendorf hasta Kant).

16. MulHOLLAND, Kant's System of Rights, p. 10, y pp. 167-98, especialmente su resumen de la inseparabilidad de la ley y la "ética" en p. 173, y la "derivación" misma, p. 181 ff. Cfr. la explicación y crítica de Mulholland, y una explicación alternativa en K. FLIKSCHUH, Kant and Modern Political Philosophy, Cambridge University Press, Cambridge, 2000, pp. 157-68. Como expondré más adelante, el problema de la provisionalidad en la adquisición desempeña un papel en la discusión mayor de lo que reflejan estas explicaciones. 
Kant, para explicar el carácter obligatorio del derecho, dependa de alguna teoría de motivación moral o requiera algún reconocimiento moral de las exigencias de otros. Todos parecen ser perfectamente conscientes de que según Kant no se necesita ninguna "legislación interna" que explique nuestra obligación de entrar en un orden civil o de obedecer la ley pública. El estado no hace ninguna exigencia moral a sus ciudadanos, y el requerimiento de derecho (claim of right) que se hace debe explicarse como una demanda diferente, aunque siga siendo un requisito racional obligatorio. Además, aparte de Kersting, nadie parece pensar que la postura de Kant sea como la defendida por Fichte en sus anotaciones de 1793 acerca de la Revolución Francesa —que, dadas nuestras obligaciones morales generales, debemos hacer lo que podamos para que la realización de nuestra vocación moral sea más social y empíricamente realizable; que nadie debería ser indiferente ante las condiciones sociales necesarias para que podamos realizar nuestro deber de la forma más eficaz posible-. (Efectivamente, para Kant tenemos dichos deberes, pero según explica son deberes éticos claramente imperfectos, no deberes jurídicos).

Lo que es problemático en esta postura es que Kant en ningún lugar aboga, ni siquiera de forma indirecta, por un tal status moral de los principios de derecho. Parece que intente no hacer ninguna derivación, que trabaje sin ninguna "aplicación" y, aunque la Fundamentación supuestamente sienta las bases de la totalidad de la Metafísica de las costumbres, Kant no indica ninguna ruta directa que nos lleve de la primera obra a la segunda. Si se supone que pensamos en la ley moral como una ley "aplicada" a una esfera de la actividad humana suficientemente distinta como para producir principios de derecho específicos, nuestras opciones parecen quedar bastante limitadas. Si la esfera consiste en ejercicios externos de la voluntad (el dominio en el cual mi ejercicio de libertad limita lo que en otro caso, otro podría hacer), parecería que dicha aplicación sólo produjera una prohibición de las acciones cuyas máximas no pueden ser universalizadas y un deber imperfecto general no de ignorar sino de ayudar a nuestros compañeros. Podríamos añadir un derecho general de autodefensa, una "autori- 
zación" para oponer resistencia a aquéllos que ilegítimamente "impiden" el ejercicio permisible de la libertad, pero no habríamos generado por ello ninguna necesidad de ley pública.

Todo esto es útil para los "separacionistas". Hay pasajes que parecen defender acérrimamente algún tipo de autonomía metodológica completa de los principios de derecho. Comentaristas como Allen Wood y Marcus Willaschek han apuntado que Kant (a) sostiene que el principio de derecho es analítico, lo que parece querer decir que Kant sólo intenta presentar la forma necesaria de voluntad libre racional en las relaciones externas, y que defiende que la autoridad de coaccionar para que se esté de acuerdo con esta forma se deriva analíticamente de la noción misma (que es permisible cualquier "obstáculo que se opone al obstáculo" de la liber$\operatorname{tad})^{17}$. Y (b) Kant llama a la ley universal del derecho un "postulado que no es susceptible de prueba ulterior alguna" $(6: 231 ; 25)$, también sugiriendo que no tiene ninguna derivación en mente, pese a su ocasional lenguaje "de deducción". Por último, Kant dice que la ley universal del derecho; “...ciertamente es una ley que me impone una obligación, pero que no espera en modo alguno, ni menos aún exige, que deba yo mismo restringir mi libertad a esas condiciones por esa obligación, sino que la razón sólo dice que está restringida a ello en su idea y que también puede ser restringida por otros de hecho [tätlich]" $(6: 231 ; 25)$.

Afirmaciones como esta han llevado a Willaschek a decir que el reino del derecho es una "expresión de la autonomía humana semejante al dominio moral, aunque independiente de éste" y, por lo tanto, que el principio de derecho es una "ley independiente y básica de la racionalidad práctica", un tipo diferente de "expresión

17. Véase sobre todo 6:396; 157-8: "La coacción externa, en la medida en que es una resistencia que se opone a lo que obstaculiza la libertad externa concordante según leyes universales (un obstáculo que se opone al obstáculo de la misma), puede coexistir con fines en general, está claro según el principio de contradicción y yo no debo ir más allá del concepto de libertad para comprenderlo; cada uno puede proponerse el fin que quiera. Por tanto, el principio jurídico supremo es una proposición analítica." 
de la autonomía humana"18. Wood ha defendido que, con esta afirmación sobre la analiticidad, Kant parece "desacreditar explícitamente toda idea de que el principio de derecho se derive del principio fundamental de moralidad"19, y que los deberes jurídicos "pertenecen a una rama de la metafísica de las costumbres que es totalmente independiente de la ética y también de su principio supremo" 20 .

Sin embargo, las afirmaciones sobre la analiticidad y sobre los postulados no son evidencias decisivas, como ya ha demostrado Paul Guyer. Los resultados analíticos basados en conceptos falsos o arbitrarios no establecen nada de importancia y así, Kant debe entender que su análisis del derecho depende de cuanto ya está implícito en el concepto "legítimo" de libertad humana: que estamos sujetos a los requisitos de la razón pura práctica, lo cual es por sí mismo una afirmación sintética ${ }^{21}$. Además, Kant no dice que los postulados no requieran ninguna prueba, sino que su prueba es "constructiva" (como ocurre en matemáticas) en lugar de deductiva o, en el caso práctico, como si hicieran afirmaciones discutibles sobre los estados que, de acuerdo con Guyer, son "necesarios para que se pueda cumplir una orden moral" 22 . De hecho, el mismo pasaje dice que la ley jurídica es un postulado que no es susceptible de prueba ulterior alguna, dando a entender que presentar un postulado es en sí algún tipo de prueba. (Kant también dice claramente que la autorización para adquirir una propiedad y así imponer a

18. "Why the Doctrine of Right Does Not Belong in the Metaphysics of Morals: On Some Basic Distinctions in Kant's Moral Philosophy", Jahrbuch für Recht und Ethik, 5 (1997), 208 y 223 respectivamente.

19. A. WOOD, "Kant's Doctrine of Right: Introduction," O. HÖFFE (ed.), Metaphysiche Anfangsgründe der Rechtslehre, Akademie Verlag, Berlin, 1999, p. 35 .

20. A. WOOD, "The Final Form of Kant's Practical Philosophy"; TIMMONS, Metaphysics of Morals: Interpretive Essays, p. 9.

21. Sobre la diferencia entre el análisis del concepto de derecho y la afirmación sintética de que los seres humanos tienen derechos, Cfr. MULHOLLAND, Kant's System of Rights, p. 171.

22. P. GUYER, "Kant's Deduction of the Principle of Right"; TIMMONS, Metaphysics of Morals: Interpretive Essays, p. 40. 
todos los demás una obligación que no tendrían de no ser así, " $n o$ la podríamos extraer de los meros conceptos del derecho en general" y por esta razón es un "postulado" (6:247; 41; énfasis mío)).

Por otra parte, el pasaje citado anteriormente (6:231) insiste en que la ley jurídica me impone una obligación (algo que tendría que implicar en el fondo alguna afirmación sintética), y cuidadosamente matiza cuanto no me es impuesto diciendo simplemente que los deberes jurídicos no requieren, al contrario que los deberes morales, que obedezcamos "en aras de esta obligación" 23 . En esta afirmación no hay nada sorprendente y, a la luz de todo esto, es difícil incluso comprender la postura de Willaschek. A Kant le resulta bastante difícil demostrar que estamos incondicionalmente ligados a los requisitos de la razón pura práctica. Si el principio de derecho es lo mismo que estos requisitos racionales pero no está "cubierto" por ese argumento general, nos volveríamos a encontrar de nuevo con la misma tarea - presumiblemente de un modo completamente independiente y no moral - de "deducir" o demostrar a través de la "exposición" de algún "hecho o razón" nuevos que esos requisitos deben ser también conforme a derecho.

Esto nos sitúa en una difícil aporía. Los derivacionistas tienen razón al insistir en que el principio del derecho está ligado en cierto modo a la teoría moral general de Kant. Después de todo, Kant frecuentemente señala que "todos los deberes [Pflichten], simplemente por ser deberes, pertenecen a la ética [Ethik]" $(6: 219 ; 21)$ y lo dice unas páginas antes de introducir lo que explícitamente llama "deberes jurídicos" (6:236; 29). No obstante, estos defensores no pueden ofrecer pasajes ni reconstruir argumentos que declaren y defiendan dicha conexión o subsunción (al menos no sin hacer que los deberes políticos parezcan deberes de virtud imperfectos). Los

23. Estas dos afirmaciones — que la ley universal del derecho "me impone una obligación" [welches mir eine Verbindlichkeit auferlegt] y que su mandato es un mandato, pero sólo requiere obediencia, no obediencia por motivo del debera mi entender son descuidadas en la interpretación que hace Wood del pasaje, lo que lleva a consecuencias engañosas. Véase A. WOOD, "The Final Form of Kant's Practical Philosophy," p. 9. 
separacionistas que desean una separación estricta entre Recht y Moral, tienen razón en que nuestra obligación de dejar el estado de naturaleza y nuestro absoluto deber de obedecer una ley correctamente constituida no son deberes morales como normalmente los entiende Kant, y no hacen ninguna apelación a la legislación "interna". Después de todo, Kant también dice, al comentar lo que él llama "derecho estricto", que éste "no está mezclado con nada ético" $(6: 232 ; 25)$. Pero esta postura aún nos deja dubitativos acerca de qué tipo de apelación nos hace la forma racional de la voluntad libre en las relaciones externas. Si hay demasiada conexión y derivación, los deberes de justicia se parecen demasiado a los deberes morales o deberes de virtud imperfectos; si hay demasiada distinción, no parece haber ninguna base para las afirmaciones de Kant sobre la "obligatoriedad" (Verbindlichkeit, explícitamente) de los "deberes jurídicos".

En tercer lugar presento brevemente una variación final sobre este tema, la sugerida por Guyer en el artículo ya mencionado, así como en algunos otros. (También está ejemplificada en un interesante artículo de los primeros de Thomas Pogge) ${ }^{24}$. Es posible que nos estemos alejando del hilo de esta investigación sobre la autoridad normativa de las afirmaciones de derecho al intentar analizar exclusivamente las implicaciones de los requisitos de la razón pura práctica y al concentrarnos sólo en cómo nuestra obediencia de una ley moral puede abarcar de un modo diferente los casos especiales en los que la conformidad coactiva está garantizada y requerida. Quizás sería mejor que apuntáramos que el poder legislativo es esencialmente lo que nos permite dedicarnos a una actividad que Kant, al menos en una ocasión, define como la señal distintiva de humanidad misma: el establecimiento y bús-

24. T. POGGE, "Kant's Theory of Justice," Kant-Studien 79 (1988): 407-33. La afirmación general que propone Pogge para aclarar los deberes jurídicos, es lo que él llama un principio, que el estado debe también entenderse como un "sistema de coacciones" que son "óptimas para promover el desarrollo y florecimiento de la razón." Incluso a primera vista, esto nos trae a la mente un deber de virtud imperfecto, y hay pocas evidencias textuales que respalden que la función del estado de proteger los derechos haya de ampliarse de ningún modo a una función de "promover el florecimiento de la razón". 
queda de nuestros propios fines ${ }^{25}$. La argumentación sería así: sin abandonar el derecho de determinar lo mío y lo tuyo en el caso de uno mismo y sin el poder legislativo (rule of law), esta capacidad no puede ejercerse eficazmente $\mathrm{y}$, en consecuencia, nuestra humanidad básica no se llevaría a cabo. Tendríamos entonces un contraste natural entre los deberes políticos, reglas necesarias para que sea posible la búsqueda de cualquier fin, y los deberes éticos, amplios e imperfectos, de ayudar a los demás en la búsqueda de sus fines. Entonces, podríamos entender el derecho como algo "derivado" de este concepto más amplio de libertad y del lugar central sugerido en la teoría moral, porque especifica los "estados necesarios para la instanciación del concepto de libertad en las relaciones interpersonales" 26 . El estado de derecho sería entonces un "postulado" al igual que los postulados prácticos establecen los estados de creencia necesarios para la realización de nuestra vocación moral.

Esta interpretación se basa en demasiadas afirmaciones polémicas como para ser tratada aquí adecuadamente, pero merece una breve atención puesto que parece tan natural considerar la política liberal como la protección de nuestro derecho a trazar el curso de nuestra propia vida, donde esa capacidad debe tener un significado moral serio. Según esta interpretación, es especialmente importante entender la base de la teoría moral de Kant no como la obligación, la ley y las limitaciones formales de la razón pura práctica, sino como una base que depende del "valor incondicional de los seres humanos" de "la libertad del arbitrio humano y la acción misma"27, donde esto se entiende como el poder para establecer fines tanto morales como no morales, y donde el cumplimiento de la ley moral es necesaria sólo como (según Guyer) un "medio para la conservación y promoción de la libertad"28. La afirmación clave es: "sólo si

25. "La capacidad de proponerse en general algún fin es lo característico de la humanidad (a diferencia de la animalidad)". (6:392; 154)

26. P. GUYER, "Kant's Deduction of the Principles of Right," p. 43.

27. P. GUYER, "Kantian Foundations of Liberalism," Kant on Freedom, Law and Happiness, Cambridge University Press, Cambridge, 2000, p. 237.

28. Ibidem, p. 240. 
podemos encontrar un objetivo y así un fin universalmente convincente que pueda dar lugar a una ley universal, podremos explicar por qué los seres racionales deberían estar obligados en primer lugar por dicha ley"29. Por lo tanto, su postura acerca del derecho es la siguiente:

El principio fundamental de moralidad dicta la protección del uso externo de la libertad o de la libertad de acción, como una expresión natural del arbitrio y, por consiguiente, como parte de la autonomía como un todo ${ }^{30}$.

Así, la libertad de elección en el reino externo ha de entenderse como parte de la "expresión natural de autonomía" y podemos por ello explicar por qué para defender dicha facultad es un requisito moral contar con un sistema de coacción público - la amenaza del estado de imponer castigos-, dado que Kant ensalza con tanta frecuencia el valor y el status especial de la autonomía humana, y dado que algunas expresiones de libertad limitarían las posibilidades que, de lo contrario, otros podrían tener en ( $\mathrm{Si}$ el ejercicio de dicha libertad no moral es realmente tal "expresión" o "parte" de nuestra capacidad moral de actuar según los mandatos de la razón pura práctica, y por ello es considerado por Kant como algo tan valioso como la autonomía moral, es otro tema. Es difícil ver cómo el ejercicio de la libertad de elección, a menudo trivial y ordinario, adquiere las excepcionales y necesarias dimensiones kantianas. Y, ¿cómo puede un ejercicio no autónomo del Willkür ser una "parte" o una "expresión" de la pura autolegislación o autonomía?). Según esta explicación, la Doctrina del derecho puede estar relacionada con la teoría moral, pero sólo si la interpretamos como una teoría de valor sustantivo y sólo secundariamente como una deontología. Esto nos proporcionaría una forma mucho más sencilla de entender cuál es nuestra facultad intrínsecamente valiosa, y por qué sería

29. P. GUYER, "Morality of Law and Morality of Happiness," Kant on Freedom, p. 145. Para una discusión más detallada de la postura de Guyer, véase mi obra "A Mandatory Reading of Kant's Ethics? Critical Study of Paul Guyer's Kant on Freedom, Love and Happiness", The Philosophical Quarterly, vol. 51, $\mathrm{n}^{\circ} .204$ (Julio 2001).

30. P. GUYER, "Morality of Law and Morality of Happiness," p. 243. 
irracional no asegurar las condiciones mínimas que nos permitieran el ejercicio de dicha facultad en un mundo compartido y finito ${ }^{31}$.

En la Doctrina del derecho no hay demasiadas evidencias textuales de esta postura, y la mayor parte de las formulaciones oficiales de esta obra se refieren insistentemente, como veremos, a los problemas formales de coherencia racional que se encuentran en la adquisición de derechos y, a los requisitos formales de la ley. Hay pocas evidencias más allá de esas afirmaciones convencionales y éstas, por sí solas, no nos llevan muy lejos. Es muy sensata la opinión de Guyer de que no entenderemos qué hay de injusto en ignorar dichas coacciones a menos que seamos capaces de ver que cumplirlas es el "medio" esencial para ser fiel a un valor supremo intrínseco. Todo esto puede llevarnos a pensar que Guyer tiene en mente la reconstrucción de algún caso kantiano no empírico cuando afirma que la libertad es un valor absolutamente superordenado, si bien Guyer admite honestamente (a) que lo que se parece a la argumentación de Kant —que podemos determinar que la libertad (como el ejercicio de nuestras facultades racionales) es el fin o propósito último "dado" al hombre por naturaleza- es inaceptable y (b) que, en definitiva, no ha lugar para que Kant haga una tal afirmación sobre la libertad. El valor último de libertad es simplemente indemostrable. Según Guyer, Kant cree que "con sólo vernos a nosotros mismos como libres podemos introducir una fuente de valor incondicional en el mundo" 32 , pero esto no ocurre por desear que exista dicho valor incondicional o por advertir qué ocurriría si no existiera ese valor.

Por otra parte, es bastante factible resumir la postura de Kant diciendo que los seres humanos son los objetos de sus propias vidas, y que por tanto no pueden ser objetos de nuestras vidas, que son fines en sí mismos y por ello poseen un valor "inestimable" e incomparable. Pero lo que esto significa en el contexto práctico

31. Este asunto tiene también gran importancia en la explicación de Wood. Véase mi discusión en "Kant's Theory of Value: On Allen Wood's Kant's Ethical Thought", Inquiry, vol. 43, (2000).

32. P. GUYER, Kant on Freedom, p. 171. 
- lo que significa que tengan dicho valor- es simplemente que una persona no puede actuar de modo que se arrogue para sí misma un status único y excepcional que no pueda ser conferido a todos por igual. Y todo lo que esto significa es que no debemos adoptar ninguna máxima que no pueda ser deseada al mismo tiempo por todos o servir como ley universal de la naturaleza. Afirmar que el curso de una acción es nuestro deber porque cumplir dicho deber es una "manera" de respetar y realizar la libertad, nos sitúa en una trayectoria en el fondo no kantiana, principalmente porque para Kant nos encontramos en una relación obligatoria con dicho status - estamos vinculados al deber de respetar el status de cada uno como un fin en sí mismo, como un ser libre ${ }^{33}$ - . Así, según la formulación de Guyer habríamos de decir: estamos obligados al imperativo categórico porque es la manera eficaz de cumplir nuestra obligación del imperativo categórico.

Por último, no queda en absoluto claro si este lenguaje del valor último y los medios para realizarlo puede llevarnos de nuevo a la distinción estricta que hace Kant entre los deberes jurídicos (que pueden ser forzados mediante coacción) y los deberes de virtud imperfectos. Es bastante razonable argumentar que no sólo debemos ejercer nuestra propia capacidad de elección y no hacer nada para impedir que los demás ejerzan la suya, sino que también debemos hacer cuanto podamos para asegurar los "estados" bajo los cuales todos podamos ejercer nuestro derecho. Y también podríamos añadir que es permisible oponer resistencia a cualquier persona que impida nuestro ejercicio de dicho derecho, pero no tenemos ningún argumento a favor del exeundum e statu naturali que requiere el caso de Kant y parece que estuviéramos abogando de nuevo solamente por los deberes imperfectos, deberes amplios de

33. Sólo estoy repitiendo la formulación canónica de Kant de lo que él llama una aparente "paradoja", que "...el concepto del bien y el mal no está definido antes de la ley moral, para lo cual, podría parecer, el primero habría de servir como fundamento; más bien, el concepto del bien y el mal deben definirse según y mediante la ley." Critique of Practical Reason, trad. L. W. Beck, New Prentice Hall, Upper Saddle River Jersey, 1993. AA 5:62-3; 65. 
hacer cuanto podamos para asegurarnos de que todos tengan la oportunidad de conseguir sus fines.

IV

Una de las razones por la cual es tan difícil encontrar una explicación adecuada de la legitimidad normativa del monopolio del estado sobre la violencia coactiva es que Kant encierra gran parte de su respuesta a esta pregunta en los detalles más minuciosos de su argumentación en lugar de declararlo de forma más explícita. Su "respuesta" está esencialmente contenida no en el material introductorio, sino en dos densos párrafos de la sección del Derecho privado: $\S 8$ y $\S 9$. Estos párrafos contienen las bases de su razonamiento. Equivale a: la inaceptabilidad de la res nullius (objetos tratados como si no fueran capaces de ser propiedad) para los seres racionales, y la afirmación de que un poder legislativo público es el "único" modo (como dice en el título del §8) de asegurar dicha posesión inteligible (o possessio noumenon). La no aceptación de la res nullius y la afirmación de que sólo el estado hace posible la possessio noumenon, son las enunciaciones que revelan cómo entiende Kant la relación entre su teoría jurídica y su teoría moral, y por qué cree que puede establecer esta relación mientras sigue introduciendo el requisito de coacción para la exigencia de derechos, y que puede defender la distinción, el status no moral, sino "obligatorio", de los deberes jurídicos.

En la última cuestión, es útil anotar en primer lugar la gran diferencia que hay entre las formulaciones de la Doctrina del derecho y las primeras formulaciones de Kant. La diferencia clave tiene que ver con la postura inicial (o Fundamentación) de Kant sobre la independencia radical desde el punto de vista moral, y su posterior postura acerca del estado social necesario para un cumplimiento eficaz de nuestras obligaciones generales con nosotros mismos y con los demás. En la Fundamentación (1785), al referirse a la formulación de la ley moral como un fin-en-sí-mismo, dice: 
"Aunque el ser racional no puede contar con que, aun cuando él mismo siguiese puntualmente esta máxima, por eso cualquier otro sería fiel a precisamente la misma, e igualmente tampoco con que el reino de la naturaleza y la ordenación con arreglo a fines del mismo concuerden con él, como miembro adecuado para un reino de los fines posible por él mismo [...] sin embargo aquella ley: Obra según máximas de un miembro universalmente legislador para un meramente posible reino de los fines, permanece en todo su vigor, porque manda categóricamente. Y aquí reside precisamente la paradoja: en que meramente la dignidad de la humanidad como naturaleza racional, sin ningún otro fin o provecho que conseguir por ella, y por tanto el respeto por una mera idea, debería servir, sin embargo, de inexcusable prescripción de la voluntad"34.

El sentido general está claro. Respeto por una "mera idea", obediencia a la ley moral puede querer decir que eres el único ser racional que esté limitando su voluntad y eso puede querer decir que estés en una situación bastante mala. Pero la vida es dura y, en cualquier caso, allí reside la gloria de la obediencia.

Doce años más tarde, Kant escribiría que, sin la seguridad mutua que proporciona un estado, cada individuo, pueblo o estado pueden "hacer cada uno lo que le parece justo y bueno por su propio derecho sin depender para ello de la opinión de otro" $(6: 312 ; 90)$. Y en el estado de naturaleza, "... los hombres no son injustos en modo alguno unos con otros si luchan entre sî" (6:308; 86, énfasis mío). Estas observaciones se basan en la afirmación original de Kant sobre las relaciones exteriores entre seres libres, que "no estoy obligado a respetar lo suyo exterior de otro, si no me garantiza también cualquier otro por su parte que se comportará con respecto a lo mío según el mismo principio (6:255-6; 44). El concepto general de este punto también está claro. La razón pura práctica puede ser capaz de formular la forma racional de las relaciones que se encuentran entre las voluntades libres de las relaciones externas, pero eso no puede obligarme a menos que la

34. AA, 4:438-9; 57 (La cita en castellano se ha tomado de la traducción de José Mardomingo, Editorial Ariel, Barcelona, 1999). 
condición de la cita de la Fundamentación, con la que Kant dice que no podemos contar — que cualquier otro ser racional actuará del mismo modo- efectivamente se convierta en algo con lo que podamos contar. El principio de todas las relaciones exteriores entre voluntades racionales queda suficientemente claro - respetar la distinción entre lo mío y lo tuyo-, pero su fuerza obligatoria es condicional: respetaré lo tuyo sólo si puedo asegurarme de que tú respetarás lo mío. (Y, por supuesto, esto requiere una distinción fiable de qué se considera lo mío y qué se considera lo tuyo).

Pero, en realidad, Kant no ha modificado en ningún aspecto su forma de pensar: sólo ha cambiado el énfasis. Consideremos las dos partes de este caso; primero su afirmación de que los objetos que no pertenecen a nadie estarán en "contradicción con el derecho" $(6: 251 ; 41)$. Esto es así porque "la libertad se privaría a sí misma de usar su elección con relación a un objeto de elección". Los objetos que podrían ser utilizados de modo apropiado por seres que responden a la razón, no sólo a determinaciones sensibles no serían tan utilizados de forma arbitraria e irracional. Esto, en efecto, "anularía los objetos desde el punto de vista práctico" y ya que no hay nada "en" los objetos que pueda decirse que justifique dicha restricción, la libertad negaría su propia facultad de hacer uso de los objetos materiales, especialmente el suelo, como medios racionales para la promoción de sus fines. Dado el tipo de ser que somos, supondría aceptar una restricción — que nada puede tenerse en posesión exclusiva- sin ningún motivo para ello.

Además, un ser libre debe ser capaz de ejercer su facultad como ser libre ${ }^{35}$. Para dicho ser no sólo debe ser posible la posesión exclusiva, sino que también debe ser posible la posesión exclusiva no física. Esta posesión no está limitada por las propiedades físicas de la naturaleza y es necesaria porque la adquisición y el uso de

35. Jay Wallace me ha señalado que no hay ninguna razón particular para que la argumentación sobre el exeundum esté fuertemente ligada a la cuestión de la propiedad. Cualquier situación imaginada en la cual los seres racionales no establezcan con otros las relaciones racionales de las que son capaces, sería una violación del requisito "honeste vive" discutido a continuación, y sería en consecuencia inaceptable. 
objetos “...concierne a una determinación del arbitrio según leyes de la libertad..." (6:253; 43). Limitar el uso jurídico a una posesión real sería también aceptar una limitación que no es razonable aceptar, una limitación que injustificablemente infringe el hecho de que los agentes puedan establecer relaciones inteligibles unos con otros (relaciones basadas en el reconocimiento común de una idea) y, por ello, relaciones inteligibles con los objetos naturales. El razonamiento continúa de un modo inusual, exactamente como lo describe Kant al final del §7: que la razón práctica en este caso - nuestro intento de determinar qué debería obtener en el cumplimiento de mis fines, dado que yo soy un ser que responde a razones- "se amplía" "sin intuiciones", simplemente mediante la omisión o eliminación de las "condiciones empíricas" que no son adecuadas como restricciones de un ser racional libre. Al hacer esto, llegamos al modelo social que deben adoptar los seres libres en la búsqueda de fines.

Dichos seres deben ser capaces de beneficiarse de la posesión exclusiva para el cumplimiento de sus fines, y esa posesión no ha de verse limitada a las condiciones empíricas de la posesión o proximidad físicas. Puesto que soy un ser que puede establecer relaciones racionales con otros, debería ser capaz de asegurar dicha posesión no física mediante dichas relaciones. Pero, señala Kant, no puedo hacerlo mediante un simple decreto.

Ahora bien, la voluntad unilateral con respecto a una posesión exterior, por tanto, contingente, no puede servir de ley coactiva para todos, porque esto perjudicaría a la libertad según leyes universales. Así pues, sólo una voluntad que obliga a cada cual, por tanto colectivo-universal (común) y poderosa, puede ofrecer a cada uno aquella seguridad $(6: 256 ; 45)$.

Así, Kant concluye con lo que es en definitiva la tesis del trabajo en sí: "...sólo en el estado civil puede darse un mío y tuyo exterior" $(6: 256 ; 45)$.

Todo esto no equivale a un cambio en la postura básica de Kant, como si ahora abogara por las condiciones empíricas de la posibilidad del deber moral como tal. Este aspecto permanece no condicionado y categórico. No obstante, éste es en efecto el modo de 
Kant de abordar, avant la lettre, una de las críticas más antiguas de su teoría moral: que es un formalismo vacío y que no puede guiar las acciones. Aquí el mismo Kant pone énfasis en que, por una parte, la razón pura práctica puede determinar la forma necesaria de la relación de la voluntad libre en la relación externa — deben ejercer su libertad de un modo coherente con un ejercicio similar de todos-. Así, con una adición empírica en absoluto controvertida - que el mundo humano es finito- también podemos estipular que habrá acciones que inevitablemente limitarán lo que otro podría hacer de otra manera, y así el principio de derecho es un principio general y formal para resolver el inevitable conflicto entre las reivindicaciones de lo mío y lo tuyo. De este modo podemos determinar racionalmente las condiciones generales de una adquisición justa, o de lo que Kant llama adquisición originaria. Así podemos concluir:

Todos los hombres están originariamente en posesión común del suelo de la tierra entera (communio fundi originaria), (cada uno) con la voluntad de usarlo, que le corresponde por naturaleza (lex iusti); esta voluntad, debido al enfrentamiento inevitable por naturaleza del arbitrio de uno con el de otro, anularía todo uso del suelo, si no contuviera a la vez la ley para éste, según la cual puede determinarse a cada uno una posesión particular sobre el suelo común $(6: 267 ; 54)$.

Este principio de arbitrio debe ser una voluntad general completa (no la voluntad de una de las partes), lo suficientemente poderosa como para establecer la seguridad de que cualquier acuerdo que ceda el derecho de uno mismo sea en realidad recíproco.

Hasta aquí bien, pero también queda claro ahora que Kant está insistiendo en que, de hecho, la razón pura práctica por sí misma es incapaz de determinar el contenido de cualquier resolución de ese tipo de acuerdo con un principio, y que esto también tiene implicaciones racionales. La inaceptabilidad (racional) del estado de naturaleza reside en que se trata de un estado de indeterminación, que mientras podemos afirmar claramente que estamos vinculados al respeto de la frontera entre lo mío y lo tuyo, no tenemos modo de deducir de nuestro principio racional lo que es in concreto 
legítimamente lo mío y lo tuyo. Puede haber requisitos mínimos para la adquisición originaria (la tierra no debe ser reclamada, por ejemplo; la prioridad temporal confiere derechos según Kant (§14)), pero cualquier adquisición determinada sólo puede ser "provisional" y debe ser adquirida en "previsión" de una posible resolución de las demandas por una voluntad general.

Es importante destacar aquí que la inaceptabilidad de la situación pre-civil no se discute como un problema estratégico o pragmático en general. Se afirma que en principio no es posible establecer unilateralmente la posesión inteligible que es condición necesaria para el ejercicio de nuestra agencia racional en un mundo finito habitado por otros agentes. No es que se trate de una tarea prácticamente difícil o insegura, carencia de confianza mutua, como si simplemente ocurriera que no me resulta prudente fiarme de ti hasta que pueda asegurarme de que respetarás lo que es mío. El problema es mucho más profundo: no puede haber ninguna distinción "realmente" precisa de lo mío/lo tuyo la cual haya que proteger en primer lugar, sobre la cual ser prudente, sin una resolución realmente "omnilateral" (allseitiger,§14) del status meramente provisional de los derechos de propiedad. No obstante, esta resolución también sería solamente provisional y estaría sujeta a un reto constante si supuestamente no hubiéramos cedido por completo nuestro derecho de decidir en nuestro propio caso a dicha voluntad general, y esto significa otorgar a dicho soberano un poder real de imposición y una absoluta soberanía. La "seguridad" requerida es por consiguiente necesaria para que cualquier resolución putativa de esta indeterminación sea realmente una resolución de la condición racionalmente inaceptable de derechos de propiedad indeterminados. Esto es, conformarse con esta indeterminación sería incoherente con nuestro status como seres racionales libres y con la condición mínima necesaria para un ejercicio real del agente 
consecuente con este status y, por ello, tal como insiste Kant de forma tan explícita, "injusto en sumo grado" (6:308; 86), no imprudente $^{36}$. (En una expresión poco habitual, Kant dice que no conseguir establecer relaciones justas sería "privar" de "validez" al derecho (Gültigkeit nehmen) y así actuar como si la "violencia bruta fuese legal" (gesetztmäßig) (6:308n; 86n). (También conviene señalar que aquí es donde Kant podía haber dicho, aunque no lo hace, que la violencia sin ley haría imposible el establecimiento y la búsqueda de fines, la realización de nuestra humanidad. Pero lo que es injusto es actuar como si la violencia fuera "gesetztmäßig" cuando no lo es). Los seres racionales sólo pueden interactuar racionalmente cuando están sujetos al Principio Universal del Derecho, lo cual significa que se me permite utilizar lo que es mío bajo la siguiente condición: "hacer a otros lo que en sí no les perjudica en lo suyo..." (6:238; 30). No obstante, no seríamos coherentes si reconociéramos estar vinculados a dicha norma, pero admitiéramos también que somos incapaces de determinar de forma justa qué es lo tuyo y lo mío. Esto último sólo ocurriría en el caso de las voluntades unilaterales. Por lo tanto, sólo queda una alternativa más: exeundum e statu naturali. QED.

Este último punto acerca de la "inaceptabilidad formalmente racional" nos lleva de nuevo finalmente a la cuestión del status normativo del Principio Universal del Derecho y con ello al estado kantiano. ¿Ha revelado algo el núcleo de la argumentación de Kant sobre la cuestión de naturaleza o sobre la relación entre Recht y Moral? Considero que hasta cierto punto lo ha hecho. La inaceptabilidad de la res nullius nos ha llevado de nuevo a la cuestión

36. Una vez más, se dice que esta inaceptabilidad no está basada en el inestimable "valor" de "humanidad", nuestra capacidad de proponernos fines por nosotros mismos, como si la seguridad de los derechos de propiedad fuera una condición práctica necesaria para dicha facultad (incluso si en cierto sentido evidentemente lo es). El problema que señala Kant es el problema de los compromisos incompatibles - por una parte-, ineludiblemente, la posesión inteligible, y por lo tanto una solución a la indeterminación entre lo mío y lo tuyo; pero por otra parte señala una restricción que se encuentra en el estado de naturaleza, un unilateralismo que no puede establecer esta posesión inteligible. De aquí la demanda de exeundum. 
más básica de la filosofía práctica de Kant, la autoridad de la razón pura práctica, en sus dimensiones formales. Esto puede ser finalmente un callejón sin salida (no lo creo), pero esa demanda general de autoridad claramente está desempeñando un papel principal en la Doctrina del derecho. Una vez que conocemos que hay una condición que debe cumplirse para satisfacer los requisitos de la ley de libertad entre seres cuyas acciones inhiben el rango de posibilidades que, de no actuar ellos, tendrían los demás seres racionales - donde la condición es una posesión inteligible - y que no puede conseguirse sin la creación de una genuina (poderosa) voluntad común, se habrá determinado tanto la continuidad como la distinción entre Recht y Moral. La continuidad es una cuestión de estar vinculado por las limitaciones formales de la razón pura práctica; la discontinuidad es el status especial de la condición requerida para que se dé la posibilidad de que los seres con dicha limitación se relacionen racionalmente. Esta afirmación está respaldada por un último fragmento de texto, quizás el pasaje más misterioso de la Doctrina del derecho.

El pasaje aparece cuando Kant intenta explicar la "División de la doctrina del derecho." Más bien, introduce bruscamente una sección llamada la "División general de los deberes jurídicos" y saca a escena, sin ningún tipo de preparación ni explicación, al jurista romano del siglo III, Domitius Ulpianus ${ }^{37}$, y tres principios o fórmulas que, según admite Kant inmediatamente, en las que Ulpianus "pudo no haber pensado claramente pero que, sin embargo, pueden explicarse desde ellas" o, recurriendo a un principio hermenéutico bastante radical, pueden "incorporarse en ellas" $(6: 236-7 ; 29)^{38}$. Las "fórmulas" consisten en (a) honeste vive, o ser un hombre honesto, con lo cual Kant quiere decir "afirma el propio

37. Ulpianus (d. 228) actualmente es conocido principalmente debido a sus comentarios sobre la ley civil, Libri ad Sabinum, y sus libros sobre los decretos pretorianos, Libri ad edictum, que acabaron por constituir las bases para aproximadamente un tercio de las posteriores (533) pandectas justinianeas.

38. Para una discusión más detallada de este pasaje, véase mi obra "Dividing and Deriving in Kant's Rechtslehre", O. HÖFFE (ed.), Immanuel Kant, Metaphysische Anfangsgründe der Rechtslehre, Akademie Verlag, Berlin, 1999, pp. 63-85. 
valor como hombre, no te conviertas en un simple medio para los demás." (b) Neminem laede, no dañes a nadie, a lo cual Kant añade el insólito supuesto, "aunque para ello debieras desprenderte de toda relación con otro y evitar toda sociedad". Y (c) Suum quique tribue, o, si no puedes evitar asociarte con otros, "entra en una sociedad con otros, en la que a cada uno se le pueda mantener lo suyo". Efectivamente es ésta la tesis central, la inaceptabilidad de permanecer en un mundo pre-civil, o la demanda de "exeundum" 39 .

El razonamiento que Kant parece tener en mente se entiende mejor como un tipo de progresión que inmediatamente traerá a la memoria la argumentación que acabamos de abordar en $\S 8$ y $\$ 9$. Su afirmación - "sé el ser autodeterminante que eres"- en primer lugar parece ser simplemente un deber perfecto para con uno mismo, un tipo de deber de integridad moral, y no queda claro inmediatamente por qué está incluido en la lista de "deberes jurídicos". Pero, como ya hemos visto, su propósito principal parece ser aclarar el "principio" general del cual se derivarán posteriormente los deberes políticos. De hecho, este requisito general estaba presente en el argumento de la propiedad — no te conformes con una posesión determinada meramente física, o no actúes como si fueras el tipo de ser que pueda utilizar algo sólo cuando lo posea físicamente- Honeste vive comienza como: actúa siempre de modo coherente con el status de un ser que responde a las demandas de la razón pura práctica, y así en la esfera "externa", no dejes a nadie apropiarse de lo que es provisionalmente tuyo. Sin embargo, para seguir siendo coherente, honeste vive tiene que terminar tam-

39. Entonces añade Kant que esta lista divide los deberes en deberes internos y externos y "en aquellos [deberes] que contienen la derivación de los últimos a partir del principio de los primeros mediante subsunción". Al parecer quiere decir que hay deberes perfectos para uno mismo (algo como: sé el ser autodeterminado que eres) y deberes perfectos para otros (no dañes a nadie, no actúes como si los demás no fueran también dichos seres) y, por último, una clase más de deberes externos hacia los demás que se derivan mediante subsunción de este deber general a otros, dada una condición específica (la inevitabilidad del contacto con otros) bajo el principio del primero, o deber de honeste vive. Este principio general tendría que ser de alguna forma la ley moral. 
bién así: para cumplir este deber, establece una posesión inteligible coherente con tu status como ser racional libre. O bien tiene este sentido una vez introducida la condición mencionada por el segundo deber.

Esta dimensión social se introduce en el segundo deber, neminem laede. No dañes a nadie, aunque para ello debieras desprenderte de toda relación con otro y evitar toda sociedad. Claramente, Kant insinúa (en un tono rousseauniano) que sin un orden civil será difícil, si no imposible, cumplir este deber con determinación. La única posibilidad que tiene el mundo pre-civil para ser fieles a esto es evitar toda sociedad; lo cual no constituye una alternativa real. Lo hipotético es claramente irrealizable, como lo era para el Rousseau del Segundo Discurso. Rousseau se preocupó por la inevitable dependencia que haría imposible la existencia de cualquier autodirección o valor en la vida. Kant se muestra preocupado, no porque sea inevitable que nos dañemos unos a otros (el estado de naturaleza no es un estado de injusticia, sino un estado carente de justicia), sino que señala que las acusaciones mutuas de injusticia o daños serían inevitables y en principio irrebatibles por cualquiera de las partes; habría una ausencia de justicia.

Esta consideración es lo que supuestamente nos lleva a la conclusión: Suum quique tribue, que en esencia resuelve el problema de una distinción inteligible entre lo mío y lo tuyo entrando en un orden civil. Se sostiene que uno no puede actuar coherentemente con el primer deber sin una posesión inteligible; uno no puede establecer una posesión inteligible en el estado de naturaleza sin acusaciones inevitables de injusticia contra otros y, por consiguiente, sin posibles violaciones del segundo deber y, así, para evitar lo que proscribe éste segundo deber y para mantenerse fiel al primero, uno debe ceder el derecho de decidir por sí mismo a una autoridad civil, a un poder soberano que supuestamente debe hablar en nombre de todos cuando apelen a la protección de sus derechos. Debemos entrar en un dominio de libertad externa "en el cual el arbitrio de uno puede unirse con el arbitrio de otro de acuerdo con una ley universal de libertad". Así que, en cierto modo, se trata 
de mantenerse fiel o leal a (ser coherente con) nuestro status como seres racionales libres, status que nos hace entrar en un orden civil prácticamente necesario. La injusticia de no hacerlo es, como es lógico, el tipo de injusticia que para Kant es la irracionalidad, la injusticia de depender de una condición necesaria para actuar, la cual repudiemos con nuestras acciones.

Evidentemente Kant está intentando mostrar que en un área de nuestras relaciones con otros (las distinciones entre lo mío/lo tuyo), para ser los seres autodeterminados que somos, y seguir respondiendo a la razón, debemos respetar una distinción que no podemos definir unilateralmente, cuyo contenido no puede deducirse como una ley de la razón pura práctica ${ }^{40}$. Esto no nos lleva en absoluto a un deber de virtud imperfecto o al establecimiento de una condición necesaria para asegurar el establecimiento y la búsqueda de fines. La frontera determinada entre yo y los otros está en juego; no hay modo de evitar establecer dichas fronteras; debemos establecerlas como seres racionales libres, y dichos seres sólo tienen una solución —el establecimiento de una voluntad común con poder coactivo.

Esta postura sigue encontrándose aún con muchas objeciones. De hecho, ahora podemos ver que debido a su continua lealtad a la autoridad de los mandatos formales de la razón pura práctica, Kant no puede deshacerse de su tesis de absoluta soberanía y de ausencia total de derecho a la revolución. La solución al problema de la posesión inteligible no es en absoluto sustantiva o dependiente de ninguna tesis referente a lo que tenemos derecho por naturaleza o por algún otro criterio sustantivo. El problema está generado en parte porque la razón no conoce bien dicho principio y por ello debe optar por la solución formal de una voluntad común definitiva cuya única función es ser definitiva, establecer la frontera entre lo mío y lo tuyo de un modo que no pueda ser recusado. Reservarse el derecho a la revolución es por lo tanto haber rehusado, formal y efectivamente, dejar el estado de naturaleza. $\mathrm{O}$, según las palabras

40. MS, 6:263; 51. 
de La paz perpetua: "Cualquier constitución legal, incluso si sólo es un poco legal, es mejor que ninguna constitución..."41.

Esta forma de razonamiento es también en parte el motivo por el cual Kant afronta tantas otras objeciones. Dado que la solución esencialmente equivale a que haya una delineación de la frontera entre lo mío y lo tuyo, y dado que no hay ningún estándar sustantivo para ello, Kant concluye que el soberano no tiene más elección que empezar desde las posiciones establecidas provisionalmente en el estado de naturaleza. Pero, dado que no puede haber tampoco ningún principio racional que guíe provisional o sustantivamente dichas adquisiciones, Kant tiene que basarse en una determinación completamente empírica: puedes apropiarte de tanto como puedas defender. El control del océano más allá de la costa se extiende "hasta donde alcanzan los cañones" $(6: 265 ; 52)$. Esto es sorprendente, ya que la inaceptabilidad de la res nullius y la posesión meramente provisional se suponía que era el resultado de su incoherencia con nuestro status como seres racionales libres. Si el argumento central se basa en la afirmación de que esa posesión física no debería ser un criterio decisivo para los seres racionales, ¿por qué permitir entonces que el criterio de defensibilidad física establezca el alcance de la propiedad en las generaciones venideras? ${ }^{42}$

41. "Perpetual Peace: A Philosophical Sketch", H. REISS (ed.), Kant's Political Writings, Cambridge University Press, Cambridge, 1970. AA, 8: 373n; 118 .

42. Es cierto, como señala Mulholland (Kant's System of Rights, p. 294), que el soberano tiene una extraordinaria libertad para redistribuir la propiedad adquirida originariamente una vez que lo provisional se convierte en un título perentorio, pero es exagerado insinuar que la postura de Kant es compatible con una política radicalmente redistributiva. La necesidad del tránsito de un derecho provisional a uno perentorio sería difícil de entender si no asumiéramos que el soberano no estuviera en cierto sentido guiado por los resultados de la adquisición originaria. 
Estos problemas pueden multiplicarse y hay respuestas kantianas para muchas de esas acusaciones, pero quiero concluir subrayando unas características poco habituales que distinguen la postura "central" de Kant, tal como se ha expuesto aquí. En primer lugar, la narrativa que esboza Kant es de hecho la narración del tránsito de un status humano meramente empírico/sensible a un status "real", como un ser inteligible ubicado en un mundo finito e inevitablemente en conflicto. El último es un status que en cierto modo debemos alcanzar y mantener. [En La doctrina de la virtud, Kant dice que "es para el hombre un deber progresar cada vez más desde la incultura de su naturaleza, desde la animalidad (quoad actum) hacia la humanidad..." $(6: 387 ; 151)]$. Desde luego que, según la metafísica práctica de Kant, simplemente somos seres inteligibles, o seres que respondemos a la razón. Pero esta narrativa sugiere que dicha capacidad también puede darse en un estado no realizado o, en términos más teóricos, que lo que significa ser un sujeto tal es también poder no conseguir alcanzar dicho status, no conseguir ser dicho sujeto. Una de las posibilidades es no actuar para resolver las demandas de propiedad provisional. Es especialmente interesante en este ejemplo que la dimensión de ese status - posesión inteligible de la propiedad- está "realizada" de una forma perfectamente social, como resultado de las determinaciones de una voluntad general o común, no una voluntad privada ni privadamente racional (unilateral). Hay algo totalmente rousseauniano en la afirmación de que nuestro status como seres libres inteligibles e incluso concretamente seres libres es una especie de logro social, que sin esta determinación social sólo somos sujetos inteligibles de modo "provisional" y "anticipador", sujetos que, debido a nuestros hechos, podemos superar lo que de otra manera serían las condiciones y limitaciones empíricas de la acción.

En segundo lugar - y éste me parece el resultado más interesante de cuanto hemos visto - queda claro en esta argumentación que el poder legislativo no se supone que simplemente garantiza y asegura lo que es lo mío y lo tuyo, puesto que Kant sigue insis- 
tiendo en que sin un orden legal - la institución de una voluntad genuinamente común - no hay ningún mío y tuyo definitivo. Se considera a Kant como un filósofo liberal, que fuerza la actividad del estado en aras de un reino privado, en el que sólo se puede interferir con el objeto de asegurar un dominio similar para todos; se le considera un filósofo liberal que limita el poder del estado apelando a lo que todos desearían, desearían racionalmente, consentirían, etc. Pero lo mío y lo tuyo, las fronteras básicas de lo privado no son tratadas por Kant como puntos de partida principales, sino como puntos secundarios y como algún tipo de logro alcanzado socialmente. Esto sugiere que lo mío y lo tuyo no son términos totalmente descriptivos, sino más bien atribuciones de los status normativos, que no están meramente asegurados por un orden legal, sino que finalmente sólo se puede decir que existen dentro de ese sistema legal de reconocimiento, imposición y resolución de los desacuerdos.

Ahora, llegados a este punto, puede parecer que nos estemos dejando llevar con demasiada facilidad hacia el reino no kantiano del Grundlage de Fichte y la Fenomenología de Hegel, textos en los que el estado de individualidad no original y alcanzado socialmente se explica por primera vez de una forma moderna (i.e. no aristotélica). Me refiero a célebres enunciaciones como la de Fichte en su obra Grundlage, cuando dice que: “... el concepto de individualidad es un concepto recíproco, puede existir en un ser racional sólo si se postula como completado por otro ser racional...nunca es mío, sino que es...mío y suyo, suyo y mío; es un concepto compartido dentro del cual dos conocimientos se unifican en uno" 43 .

Estas enunciaciones son coherentes con afirmaciones como "el ser humano (...) se convierte en un ser humano sólo entre seres humanos" 44 y, claro está, con otras afirmaciones más conocidas que Hegel expone en su Fenomenología como que "la autoconciencia

43. J. G. FICHTE, Grundlage des Naturrechts nach Principien der Wissenschaftslehre 1796, de Gruyer, Berlin, 1971, p. 47; F. NEUHOUSER (ed.), Foundations of Natural Right, trad. Michael Bauer, Cambridge University Press, Cambridge, 2000, p. 45.

44. Ibidem, p. $37 ;$ p. 39. 
sólo es satisfecha en otra autoconciencia", "una autoconciencia existe para una autoconciencia", y su introducción del espíritu como un "yo que es nosotros y nosotros que es yo" 45 .

Supuestamente el individualismo metodológico, el egoísmo racional y las teorías de la "voluntad racional" como las de Rousseau y las de Kant (en la clasificación oficial) pueden ser retadas por dichas explicaciones, y podría parecer perverso relacionar estas últimas con la Doctrina del derecho de Kant. Pero solamente apuntaré que nada de lo dicho hasta ahora se ha distanciado de forma significativa del texto de Kant. Kant también trata "lo que es mío", lo que de hecho se considera como el yo real o determinado, y "lo que es tuyo", lo que se considera como el tú real o determinado, no como una cuestión independiente a partir de la cual nace el razonamiento político. Es una frontera socialmente dependiente, variable y negociable que existe en virtud del reconocimiento mutuo de ambas partes.

Kant habla sobre los derechos de propiedad, no sobre las condiciones necesarias para que se dé un autoentendimiento, una "identidad práctica" y, por supuesto, no habla sobre las condiciones necesarias para que sea posible una "autoconciencia" determinada, etc. Ahora, dado que para Kant mi identidad moral básica, mi status como ser racional libre, es una identidad anónima, esencial e indistinguiblemente una entre muchas, parece darse cuenta de que también requiere algún tipo de explicación moralmente relevante de "qué nos debemos unos a otros" (como se suele decir) como los individuos concretos y determinados que somos, o debemos "llegar a ser" si es posible que exista dicha frontera entre lo mío y lo tuyo. El hecho de que Kant presente su teoría moral como exponen los principios de Ulpianus me parece que es una evidencia interesante a este respecto.

La cuestión obvia que se ha de plantear sobre estas reclamaciones de dependencia social básica es: ¿No debemos ser ya seres

45. G. W. F. HEGEL, Die Phänomenologie des Geistes, Felix Meiner, Hamburg, 1999, p. 108; The Phenomenology of Spirit, trad. A.V. Miller, Oxford University Press, Oxford, 1998, p. 110. 
racionales, determinados y autoconscientes para entendernos unos a otros como tales, para escuchar y responder adecuadamente a lo que Fichte llamó el requerimiento o exigencia (Herausforderung) de otro? ¿Cómo pueden "llevarse a cabo" esas exigencias o requerimientos de dependencia si sólo como resultado de ella podemos ser dichos seres? Y, de nuevo, la respuesta de Kant coincide con la respuesta que daría más tarde el idealismo — con esta distinción quasi-aristotélica entre lo que es sólo provisionalmente (potencialmente) e inciertamente postulado como una identidad o reclamación de "lo mío", inmediatamente abierta a controvesia y cuestión, y lo que puede ser mutuamente reconocido y resuelto como lo mío y lo tuyo-. Es cierto que todo esto es especulativo, fundado solamente en un fino estrato de la teoría ética de Kant, y parece abierto a numerosas cualificaciones. Y, tal como se indica, la concepción formal de Kant de la racionalidad práctica y su concepción general de la filosofía práctica limitarán lo que él puede decir sobre todo esto, pero no es descabellado afirmar que la Doctrina del derecho de Kant puede calificarse de post- o proto-fichteana o protohegeliana en este sentido (no histórico) y por tanto que insinúa una forma alternativa de liberalismo, una en la cual la individualidad racional no es esencial, sino derivativa y un status social logrado.

Robert B. Pippin University of Chicago Department of Philosophy

Chicago, IL 60637

r-pippin@uchicago.edu 